\title{
Rise in Cases of Alcohol Withdrawal following Lockdown in Dry District of Wardha
}

Prakash B. Behere ${ }^{1}$ Aniruddh P. Behere ${ }^{2,3}$ Debolina Chowdhury

\begin{abstract}
Address for correspondence Prakash B. Behere, MD, Department of Psychiatry, Jawaharlal Nehru Medical College, Director School of Advanced Studies-DMIMS, Sawangi, Wardha, Maharashtra 442 107, India (e-mail: pbbehere@gmail.com).
\end{abstract}

\begin{abstract}
Keywords

- dry district

- alcohol

- lockdown

- withdrawal

On March 11, 2020, the World Health Organization declared the SARS-CoV-2 outbreak to be a pandemic which has sent all countries in a frenzy. We cannot be callous about treatment of non-COVID-19-related patients. The Wardha district of Maharashtra is a declared "dry area" which makes the sale, purchase, and consumption of alcohol illegal. On March 24, 2020, Indians were informed of a 21-day long lockdown which was subsequently extended for another 3 weeks during which all modes of public transportation, educational institutions, offices, and other nonessential businesses were closed and people expected to remain at home unless necessary. Since then admissions of alcohol-dependent patients showed a spike from $14 \%$ in the prelockdown period to $27 \%$ of patients of alcohol dependence syndrome. It is most likely due to poor availability of liquor, inability to earn money to buy the alcohol, or restricted movement of individuals.
\end{abstract}

\section{Introduction}

On March 11, 2020, the World Health Organization declared the SARS-CoV-2 outbreak to be a pandemic which has sent all countries in a frenzy to implement various measures aimed at stopping the spread of the infection and minimizing the effect of the disease on the population. This novel corona virus started in the city of Wuhan in China and now has spread to over 200 countries in the world. It has caused disease in millions of people and claimed hundreds of thousands of lives worldwide. While government officials are busy implementing measures to help contain the spread, researchers are fighting to find a cure for the disease and medical workers are working to help save as many lives as possible. Life as we knew it has suddenly turned upside down but has not stopped. In a chaotic time like the current situation, when the world is focused on the containment of this unpredictable novel virus and preparing for the worst, we cannot be callous about treatment of non-COVID-19related patients. Every specialty of the field of medicine is still tending to various emergency situations every day. For a psychiatrist, emergencies related to the Corona virus pandemic has included disorders like panic attacks and suicide attempts due to the measures taken to combat the spread of the disease, in part due to measures such as the nationwide cessation of transportation and closure of all nonessential businesses and services including liquor shops.

\section{Prohibition District}

The Wardha district of Maharashtra is a declared "dry area" which makes the sale, purchase, and consumption of alcohol illegal in this area since 1950 in honor of one of Mahatma Gandhi's home, Sewagram Ashram being located in this district. ${ }^{1}$ Despite the efforts to implement and follow this law by authorities, there has never been any scarcity of alcohol and a whole variety of alcohol is readily available from country liquor to foreign liquor to those who wish to consume it especially local made liquor. The Acharya Vinoba Bhave Rural Hospital (AVBRH) located in Sawangi, Wardha, Maharashtra, 
India, attends to numerous patients of alcohol dependence, some who come of free will in hopes to become abstinent and others who are brought to the hospital by family members in a state of confusion, disorientation, and extreme agitation due to the effects of intoxication or withdrawal from alcohol.

\section{Alcohol Withdrawal}

Alcohol withdrawal classically starts with tremulousness, irritability, nausea, vomiting, and other autonomic hyperactivity symptoms such as anxiety, arousal, sweating, facial flushing, and so on. ${ }^{2}$ Typically, a patient of alcohol dependence will drink some amount of alcohol to avoid these symptoms. If the patient still does not drink any alcohol for approximately 8 to 12 hours after the last intake, the patient may complain of hallucinations and further may have unprovoked episodes of seizures or even sometime go directly in to delirium tremens after 12 to 24 hours of the last drink taken. Alcohol withdrawal delirium, referred to as delirium tremens, is considered as a psychiatric emergency if it remains untreated, as it has a $20 \%$ mortality rate. Generally, a patient will present with signs and symptoms such as increased heart rate, perspiration, anxiety, insomnia, visual or tactile hallucinations, and hyperexcitability or lethargy anytime from the third day to up to a week of abstinence. ${ }^{2}$ Such patients need to be admitted to a hospital and actively treated with benzodiazepines and symptomatic treatment as and when required. The patient and his vitals need to be monitored around the clock to ensure smooth recovery. In general, if alcohol withdrawal is not treated in a timely and supervised manner it may prove to be lethal, in part due to risk of seizures.

\section{Psychological Impact of the Lockdown}

On March, 24, 2020, Indians were informed of a 21-day long lockdown which was subsequently extended for another 3 weeks during which all modes of public transportation, educational institutions, offices, and other nonessential businesses were closed and people expected to remain at home unless necessary. Although there are no legal liquor shops in Wardha district, this period has further made the availability of alcohol much more difficult. This assumption can be supported by the fact that since the lockdown, there have been an increased number of patients presenting to the AVBRH outpatient department (OPD) and casualty in various stages of alcohol withdrawal. Some with simple complains of being unable to sleep or concentrate who were managed on OPD basis to a few presenting in varying states of delirium tremens and requiring immediate admission and treatment. This can be attributed due to alcohol-dependent individuals who abruptly stopped alcohol intake completely. The reason being unavailability of alcohol or inability to afford.

Other parts of India, where alcohol is not prohibited, have also been hugely impacted by this nationwide quarantine.
Deaddiction centers and hospitals in states like Kerala and Telangana are admitting hundreds of patients of withdrawal since the lockdown. ${ }^{3}$ The news in these states also report cases of suicide and sudden cardiac death due to the nonavailability of alcohol. Due to this, government authorities have been considering making a fixed quota of liquor available to those who get a prescription from a doctor for the same. ${ }^{4}$ However, doctors have refused to prescribe alcohol citing it has no scientific grounds and instead have suggested to take advantage of this situation and motivate patients to start deaddiction therapy and to treat symptoms of withdrawal with medications instead of alcohol..$^{5}$ Recognizing the severity of the situation, the Government of Tamil Nadu has taken active measures to handle this situation by providing questionnaires like the Clinical Institute Withdrawal Assessment for Alcohol and set guidelines to its medical officers for assessment and treatment of patients in different stages of withdrawal. ${ }^{6}$

Due to guidelines following lockdown, many have presented with anxiety disorders, social anxiety, phobic disorders, generalized anxiety disorders, somatoform disorders, obsessive compulsive disorders (due to repeated hand washing), alcoholism, substance use disorders, eating disorders, and other lifestyle-related disorders. ${ }^{7}$ There are five cases of suicide reported in India following diagnoses of COVID-19.

\section{Status in the Dry District of Wardha}

In the month of December 2019 (before the commencement of lockdown), out a total of 31 patients of alcohol dependence syndrome (ADS) who came to the AVBRH Psychiatry OPD, 5 (16\%) patients required admission for management of withdrawal symptoms and complications. Similarly, in January, 6 out of $54(11 \%)$ patients required admission and 8 out of $50(16 \%)$ patients were admitted in February. On the other hand, a total of 10 out of 41 (24\%) were admitted in conditions of withdrawal or delirium tremens in March and 5 out of 12 (41\%) in April. This suggests that the admission of alcohol-dependent patients were almost double the number admitted after the lockdown is declared. Overall, this shows a spike from $14 \%$ in the prelockdown period to $27 \%$ of patients of ADS requiring admission after all India lockdown was implemented from March 24, 2020. Comparing the increase in overall admissions, there has been a steady increasing trend of 13.6 and $17.3 \%$ of all admissions in January and February, respectively, of patients of ADS which is significantly lower than that in March when 27.7\% of total patients were admitted for withdrawal symptoms and $41 \%$ in April (till date).

The most likely reason may be the poor availability of liquor. Second possibility is that the daily wage labors are not able to earn money to be able to buy the alcohol. Third, restricted movement of individuals in the town is making it difficult to procure alcohol. Also, due to the lockdown, individuals are spending more time with family members due to which either the patient may not get time to drink or feel relaxed hence do not require alcohol to relieve stress. 


\section{Conclusion}

Due to the unknown course and treatment of this novel virus which due to its mutations ${ }^{8}$ has created unprecedented challenges to the world's scientific community, the future seems even more unpredictable than usual. Several researchers have hypothesized that there may be a window of relief once temperatures and humidity rises. ${ }^{9,10}$ However, it is difficult to imagine going back to normalcy even after the pandemic ends especially things that we had taken for granted. Many will have lost their lives, while others will mourn, and the financial consequences will be catastrophic. What we can manage are conditions with known treatment and preventable mortalities. Hence, we should pay attention to the current needs of society and provide psychological and pharmacological help to all who need it. Alcohol withdrawal can be managed with ease and all patients should be motivated to continue abstinence once the lockdown is over. Simultaneously, motivated by current conditions, public authorities should find permanent solutions to continue the dearth of liquor in this district of prohibition.

\section{Conflict of Interest}

None declared.

\section{References}

1 Chandrapur to become dry district | Deccan Herald [Internet]. Available at: https://www.deccanherald.com/content/454704/ chandrapur-become-dry-district.html. Accessed March 30, 2020

2 Sadock BJ, SadockVAS, RuizP. Kaplan an Sadock's Synopsis of Psychiatry (Behavioural Sciences/Clinical Psychiatry). 11th ed. Vol. 1; 2017. Wolters Kluwer
3 Rise in cases of alcohol withdrawal symptoms after Covid-19 lockdown | India News - Times of India [Internet]. The Times of India. Available at: https://timesofindia.indiatimes.com/india/ rise-in-cases-of-alcohol-withdrawal-symptoms-after-lockdown/articleshow/74900423.cms. Accessed March 30, 2020

4 A Different Tragedy Strikes Kerala during COVID-19 Lockdown Due to Non-Availability of Alcohol [Internet]. News18. Available at: https://www.news18.com/news/india/a-different-sort-oftragedy-strikes-kerala-during-covid-19-lockdown-due-to-nonavailability-of-alcohol-2556049.html. Accessed March 30, 2020

5 'Not scientific': IMA raps Kerala's 'liquor prescription' move amid Covid-19 lockdown [Internet]. Hindustan Times. 2020 Available at: https://www.hindustantimes.com/india-news/not-scientific-to-give-alcohol-to-people-with-withdrawal-symptomsima-raps-kerala/story-NPhPFTZMhEW2WVN7SeFQnK.html. Accessed March 30, 2020

6 M SJ. With no liquor available during lockdown, government issues guidelines to treat persons with withdrawal symptoms. The Hindu [Internet]. March 28, 2020. Available at: https://www.thehindu.com/news/national/tamil-nadu/withno-liquor-available-during-lockdown-government-issuesguidelines-to-treat-persons-with-withdrawal-symptoms/ article31192480.ece. Accessed March 30, 2020

7 Chaturvedi SK. Covid-19, Coronavirus and mental health rehabilitation at times of crisis. J Psychosoc Rehabil Ment Health 2020;:1-2

8 Andersen KG, Rambaut A, Lipkin WI, Holmes EC, Garry RF. The proximal origin of SARS-CoV-2. Nat Med 2020;26(4):450-452

9 Wang J, Tang K, Feng K, Lv W. High temperature and high humidity reduce the transmission of COVID-19 [Internet]. Rochester, NY: Social Science Research Network; March 2020. Report No.: ID 3551767. Available at: https://papers.ssrn.com/ abstract $=3551767$. Accessed March 29, 2020

10 Bukhari Q Jameel Y. Will coronavirus pandemic diminish by summer? [Internet]. Rochester, NY: Social Science Research Network; March 2020. Report No.: ID 3556998. Available at: https://papers.ssrn.com/abstract=3556998. Accessed March 29, 2020 